\title{
A leitura de histórias em quadrinhos da Marvel e da DC Comics e a etnometodologia: relevância e desdobramentos
}

Lígia Maria Moreira Dumont

Professora titular da Escola de Ciência da Informação da Universidade Federal de Minas Gerais - UFMG

Rubem Borges Teixeira Ramos

Professor adjunto da Faculdade de Informação e Comunicação da Universidade Federal de Goiás UFG

http://dx.doi.org/10.1590/1981-5344/3327

Apresenta a etnometodologia como um conceito teórico adequado à pesquisa sobre leitura, especialmente no que tange ao gênero das histórias em quadrinhos de superheróis. Discute os conceitos-chave da etnometodologia de Harold Garfinkel, procurando aplicá-los ao estudo e a compreensão da figura do leitor de quadrinhos. Como resultados, aponta a caracterização da apropriação de informações e da introjeção do conhecimento presentes nas relações estabelecidas pelo leitor quando da leitura das histórias em quadrinhos e o emprego de informações obtidas por meio dessa leitura nas suas vidas.

Palavras-chave: Histórias em quadrinhos. Leitores. Etnometodologia. Introjeção do conhecimento. Apropriação da informação.

\section{Marvel and DC superhero comic reading and etnomethodology: significance and ramifications}

It introduces the etnomethodology as a suitable concept for reading research, specially in reference of the superhero comic book genre. It discusses on Harold 
Garfinkel etnomethodology's key concepts, aim to use them in the study and understanding of the comic book reader. As results, it shows the description of information's ownership and knowledge gathering as part of the stablished relations by the reader when reading comic books and the use of gathered information by means of this reading into their own lives.

Key Words: Comic books. Readers. Etnomethodology. Knowledge gathering.

Recebido em 30.10.2017 Aceito em 08.11.2017

\section{Introdução}

O ato de ler é tido como uma ação social de grande valia para o indivíduo na sociedade, haja vista que por meio da leitura, o indivíduo vai acumulando informações diversas e vai desenvolvendo a capacidade de interpretar e argumentar com mais profundidade fatos, contextos e conteúdos presentes não somente em seu dia a dia, mas ao longo de toda a sua existência. Compreender a leitura envolve mais do que unicamente a decodificação de palavras isoladas, necessitando entende-la como uma ação caracterizada pelo dinamismo e abertura a olhares e interpretações diversificados, ao contrário de um ato permeado por passividade.

Os leitores de histórias em quadrinhos também são vistos como leitores inseridos em um universo de contextos, nuances e signos próprios de tal mídia, considerando-se para tanto a existência e recorrência do emprego dos personagens, locais, eventos e tramas presentes nessas histórias. O agrupamento e a interação entre os dois contextos, contexto social do leitor e o da história em quadrinhos, que concede ao leitor a capacidade de emitir e receber informação de ambos, de modo a compreender tanto o mundo que leem, quanto o seu próprio mundo real.

\section{0 estudo da leitura, sob o enfoque da Ciência da Informação}

Autores de diferentes áreas do conhecimento abordam a temática leitura como um processo cognitivo, certamente dentre outras possibilidades, como a Comunicação, a psicolinguística e também a Ciência da Informação, que mesmo com suas particularidades, são capazes de dialogar em seus desdobramentos, tais como a leitura e a escrita. De fato, hoje se percebe que a leitura é um processo fartamente mais rico do que a simples decodificação de caracteres, pois uma das suas importantes atribuições é incorporar e interpretar as relações existentes entre o que está escrito em formato de texto e a realidade, o que se estende para além do simples caráter utilitário, ou de lazer.

De acordo com Bari (2008, p. 113), a leitura na cultura ocidental estabeleceu vínculos com experiências de vida motivadas pelo prazer que 
ela pode proporcionar, quando o autor obteve relativa licença para 
escrever e ilustrar suas obras, de modo a atribuir significados afetivos e pessoais ao público leitor. Como desdobramento da leitura empreendida pela população ocidental, tem-se o surgimento de diversos gêneros literários, de linguagens midiáticas e também a diversificação de suportes onde se pode empreender a leitura.

$\mathrm{O}$ ato de ler exerce grande influência sobre a postura de um indivíduo, de um grupo ou de uma nação. Vislumbrando essa evolução dos estudos da leitura, Roger Chartier (2003) defende que o leitor se forma através de vários processos de atribuição própria de significado e de sentido, quando em contato com objetos pertencentes à cultura. Esses processos, que o próprio Chartier denomina como apropriação, em muito traduzem $o$ ato individual do leitor de refletir e atribuir significado a uma obra escrita. Pode-se completar aos dizeres do autor, mesmo ela sendo fruto de um processo de produção em massa, como vários bens culturais o são, inclusive as histórias em quadrinhos.

Apropriar-se da informação via leitura é um processo analisado pela Ciência da Informação, uma vez que essa área do conhecimento se interessa por compreender os processos e práticas sociais relativas à construção de significados e à produção de sentidos. Dumont e Pinheiro (2015) endossam tal raciocínio, ao defender que o uso da leitura nada mais é do que a compreensão do ato de ler como um fenômeno social, e que este ato é tido como meio empregado pelos indivíduos para entender o mundo. Esse entendimento é constituído por uma reunião de ações voluntárias - como a leitura e a escolha quanto ao material ou mídia a ser lida - que conferem ao indivíduo a capacidade de compor e recompor o seu universo, podendo alterar ou mesmo reforçar conhecimentos previamente adquiridos, quando são contrastados com novas informações adquiridas e processadas pelo leitor, via leitura.

Segundo Bourdieu (1979), a preferência e a escolha por determinados bens culturais perpassam vários aspectos inerentes à vida e ao cotidiano dos homens, como sua frequência aos chamados eventos e instituições culturais (museus, arquivos, concertos e exposições, dentre outros), ou suas predileções por leituras, pinturas, músicas e literaturas específicas. Tanto a preferência quanto à escolha estão intimamente ligadas ao nível educacional que o sujeito possui, e não ao seu berço social, como afirmam alguns determinismos, que procuram ressaltar uma delimitação entre o gosto pessoal e o lugar social das pessoas. Tais determinismos contribuem apenas para reforçar estereótipos ultrapassados, ainda que vigentes, como o "gosto puro" (BOURDIEU, 1979, p. 566), que tem por base privilegiar o que não é fácil. A recusa do fácil, como algo simples e sem profundidade tem por fundamento o princípio de que, se um objeto - música, literatura, arte, por exemplo é de fácil acesso e compreensão, torna-se popular, gerando uma recusa natural pelas camadas mais elitistas da sociedade.

Tendo a leitura como uma premissa básica do crescimento do ser humano, esta adquire caráter relevante para pesquisas em várias áreas do conhecimento. Dentre elas, a Ciência da Informação dedica-se a seu estudo e aprofundamento, caracterizando-a, segundo Dumont (2002, p. 
2), como a "[...] via pela qual se atinge o conhecimento". Entende-se por conhecimento o rol de informações que o sujeito acumula, podendo ser recuperado e processado nas mais diversas e variadas situações da sua vida. A premissa básica dos estudos da leitura na área não é a de se valorizar um típico específico de leitura, atribuindo-lhe um valor diferenciado dos demais, e, por consequência, justificar uma predileção por determinada leitura. Pelo contrário, procura-se demonstrar a necessidade fundamental do ato da leitura como forma de obtenção de informação, para que se possa confrontar o lido, através de ponderações e reflexões, com conhecimentos prévios já obtidos pelo leitor. A maior contribuição da Ciência da Informação é a de corroborar o papel da leitura como instrumento capaz de conduzir o leitor a uma interpretação de sua sociedade e de seu mundo, através do ambiente nela retratado, que tende a apresentar semelhanças com o próprio ambiente dos leitores.

Em se tratando do estudo da leitura, Wolfgang Iser (1996; 1999) pontua a influência que uma obra exerce frente a seu público leitor, estabelecendo que 0 ato de ler em si se caracteriza como algo que permite ao leitor reelaborar a leitura realizada através de reflexões, pensamentos e inferências com a realidade. Não obstante, conclui-se que o texto não retém uma exclusividade de sentido em si mesmo, necessitando que um leitor realize o quão significante essa mesma leitura se faz. A Ciência da Informação prima pela defesa da leitura como ato que incita o pensamento do leitor, e o faz armazenar novas informações. A leitura incita o sujeito leitor a ir além do texto propriamente escrito, ao comparar e confrontar a leitura realizada com elementos e acontecimentos de sua própria realidade, seus exemplos, seu cotidiano, enfim, sua vida. Durante o ato da leitura, o ser humano é conduzido a atribuir significados em sentido amplo ao mundo e em sentido específico ao texto lido.

A leitura constitui uma parte presente e praticamente inerente à vida cotidiana dos homens. Várias são as razões que levam um determinado leitor, ou grupo de leitores, a escolher um tipo (ou tipos) em particular de leitura, cabendo aqui serem destacadas, de acordo com Dumont (2007, p. 2, grifos nossos), "[...] a motivação, o contexto e historicidade do leitor e o sentido dado a cada palavra pelo autor e, posteriormente, pela leitura do leitor". Analisando esses três fatores, pode-se compreender a existência de uma variabilidade quanto à interpretação da leitura empreendida de acordo com o leitor, seus interesses, conhecimentos e objetivos para com a leitura, fazendo com que a compreensão não seja encarada como uma atividade de precisão, e sim como resultado da relação entre leitor e texto. Na tentativa de se estabelecer uma compreensão de um texto, seu leitor precisa ir além do mesmo. É necessário que o leitor faça uma série de inferências, elaboradas a partir das relações entre os elementos contidos no próprio texto e através das relações destes com seu prévio conhecimento, sejam eles linguístico, enciclopédico ou mesmo de mundo.

Portanto, um dos enfoques das análises sobre leitura pelo olhar da Ciência da Informação é pesquisar as relações socioculturais reconhecidas 
pelo leitor no texto lido, que se transformam em informações, sendo então trabalhadas, vindo a se transformar em conhecimento. E mais, posteriormente, 0 leitor pode reanalisar $o$ fato $e$ fazer outras interpretações dessas informações e empregar novo conhecimento em situações que ele julga serem similares à que foi lida.

\section{A etnometodologia e a leitura}

Como uma primeira aproximação, Have (2004, p. 14) defende que a "etnometodologia é uma forma especial de inquérito, dedicada as explicar os caminhos pelos quais os membros de uma coletividade criam e mantêm um senso de ordem e inteligibilidade junto à vida social". Tal corrente surgiu como uma perspectiva e estilo diferenciados dentro da sociologia. Seu criador, Harold Garfinkel (1963), começou a questionar as explicações tradicionais presentes na sociologia quanto aos fatos sociais, os quais considerava como construções práticas do indivíduo, ou seja, como produto das atividades contínuas que todos desempenham no dia a dia. Isso justificaria a necessidade de analisar as atividades diárias como um método pelo qual os indivíduos se valem para entender como são capazes de atribuir valor e sentido às ações que desempenham.

Em seu estudo mais emblemático, Garfinkel analisou os jurados de cortes de justiça norte-americanas, com o propósito de compreender as formas com que indivíduos se valiam de procedimentos e técnicas ao que, posteriormente, foi denominado como metodologia científica. Tais procedimentos primavam por desenvolver relatos adequados (accountable) por parte dos jurados, quanto de suas atividades como membros da corte. Garfinkel coletou a evidência de que os jurados praticavam uma metodologia do senso comum, onde o termo 'etno' se refere a um conhecimento de senso comum, empregado por um ou mais indivíduos com objetivos específicos, e o termo 'metodologia' às formas com que o senso comum atua junto à representação corrente do mundo e das ações analisadas. Portanto, pode-se concluir que etnometodologia é o estudo da lógica do senso comum.

Tomando-se a leitura dos leitores e os possíveis empregos de fatos lidos com fatos sociais, essa ação é passível de ser investigada sob o olhar da etnometodologia, que prega o entendimento de fenômenos sociais, em toda e qualquer realidade socialmente construída, indagando sobre cada fato aquilo que o faz e o torna relatável (accountable). Na Ciência da Informação, o uso da etnometodologia visa compreender as formas pelas quais um leitor imprime e exprime significado e sentido junto ao ato de ler, analisado à luz do senso comum.

Para Garfinkel, existe uma ligação entre as ações praticadas pelos atores sociais e a linguagem que esses usam para se referir a estas ações, ou descrevê-las. Tal princípio se aplica também aos leitores de histórias em quadrinhos de super-heróis, já que os relatos coletados podem ser relatáveis, na medida em que são capazes de evocar o senso comum entre aquilo que se encontra retratado no quadrinho e um ou mais eventos ocorridos em suas próprias vidas. A correlação portanto se dá via 
senso comum entre ambos - fato retratado nas páginas do quadrinho e eventos da vida real do leitor.

De fato, Garfinkel (1963) trabalhava sob a noção de que as ações realizadas pelos atores sociais devem ser vinculadas à linguagem pela qual são descritas. A linguagem aqui é compreendida na forma de relatos, os quais contêm uma série de práticas comuns junto a determinada comunidade ou mesmo pessoas que desenvolvem práticas comuns, mas não necessariamente pertencentes à mesma comunidade. Na pesquisa desenvolvida com leitores de histórias em quadrinhos de super-heróis ${ }^{1}$, evoca-se a prática seriada da leitura e a descrição de como um ou mais elementos ou mesmo momentos pertinentes aos quadrinhos foram capazes de ser, de alguma forma, revocados nos relatos do uso de um conhecimento - do senso comum, segundo Garfinkel - em suas vidas.

A etnometodologia considera que a realidade é uma instância socialmente construída, a qual se encontra presente na vivência habitual dos indivíduos. Esses mesmos indivíduos são os responsáveis pela escolha quanto às instâncias sob as quais vivem suas vidas. Para se entender tais instâncias do mundo social e a presença ou permanência dos atores sociais junto a elas, é necessário se ter acesso aos etnométodos, que são comportamentos e posicionamentos que os membros de um grupo social se valem, para produzir e reconhecer seu mundo, tornando-o familiar à medida em que o constroem, o descrevem e o interpretam. Ao aplicar os etnométodos, é possível compreender as ações realizadas por um ou mais indivíduos a que se deseja investigar, sob o olhar e o enfoque dos relatos deles próprios.

Ao empregar os preceitos da etnometodologia em pesquisa direcionada aos leitores de histórias em quadrinhos de super-heróis, temse por objetivo compreender a ação social leitura. Para tanto, faz-se também necessário conhecer as histórias em quadrinhos de super-heróis da Marvel e da DC Comics, a diversidade de tramas e enredos, de personagens e suas falas, posturas e atitudes. Desse modo, é possível compreender os leitores como sociólogos de si mesmos e de sua própria realidade, estabelecendo alusões junto aos fatos retratados nas páginas desses quadrinhos com fatos de suas vidas. De modo a alcançar essa percepção, cinco termos-chave foram utilizados para a operacionalização da pesquisa, com o enfoque na relação entre Ciência da Informação e etnometodologia, a saber:

a) Ações práticas ou realização: indica a experiência e as realizações práticas dos membros de um grupo em seu contexto cotidiano. Isso vem do princípio de que a realidade social é a prática cotidiana dos atores sociais e assim, torna-se necessário ter acesso e compartilhar o contexto e o cotidiano desses atores, de modo a ser possível compreender suas práticas de leitura. A partir

\footnotetext{
${ }^{1}$ RAMOS, R. B. T. Com grandes poderes vêm grandes responsabilidades um estudo etnometodológico dos leitores de histórias em quadrinho de super-heróis da Marvel e da DC Comics. 2017. 242f. Tese (Doutorado em Ciência da Informação) - Escola de Ciência da Informação. Universidade Federal de Minas Gerais, Belo Horizonte, 2017.
} 
desse apoio, surge a interpretação quanto à leitura, encarada como ato social, construída pelo leitor no seu dia a dia. Para entender a ação leitura, é necessário dedicar tempo e atenção as atividades realizadas pelos sujeitos da pesquisa, procurando não se ater unicamente a coleta de dados, mas à (re)construção, à (re)descoberta e à (re)significação dos atos realizados pelos leitores. Particularmente aplicado aos leitores de histórias em quadrinhos de super-heróis, verificando se eles são capazes de significar a sua leitura, (re)construindo as suas ações;

b) Indexalidade ou indicialidade: se refere a todas as circunstâncias que envolvem uma palavra, um termo ou uma situação. O termo-chave vem da linguagem expressa pelos leitores pesquisados, e significa que, ao mesmo tempo em que uma palavra possui um significado de algum modo genérico, essa mesma palavra possui um significado distinto em contextos específicos. Assim, para expressar determinadas palavras, necessitam os atores exibir 0 conhecimento de seus significados quando as usam, o que vem de construções envolvendo a aplicação desses termos junto à vida social dos atores, quando se envolvem em processos de fala, conversação, indagação e similares. No caso da pesquisa e do público analisado, a indexalidade permitiu adentrar os locais onde eles adquirem as revistas e encadernados de quadrinhos, conhecer o contexto compartilhado pelos leitores de quadrinhos, já que as falas coletadas via entrevista foram imprescindíveis para compreender a relação estabelecida entre esses leitores e os personagens e tramas dos quadrinhos que mencionaram;

c) Reflexividade: está relacionada às práticas e aos efeitos que o discurso e as ações sociais de um grupo exercem sobre os membros do mesmo. Se trata de um processo no qual se produz uma ação e, ao mesmo tempo, uma reação junto a seus criadores. O objetivo maior desse termo-chave é o de comprovar que as ações demonstradas por pessoas que possuem afinidades, no caso o gosto pela leitura de histórias em quadrinhos, apresentam características que podem ser utilizadas para descrever o mundo social e o cotidiano destes indivíduos. Desse modo, se compreende que os discursos dos sujeitos da pesquisa devem ser explorados nas entrevistas, no intuito de entender como os leitores, ao se referirem à leitura dos quadrinhos, são capazes de relatar como é refeito o processo de açãoreflexão, no qual as marcas do sujeito no e com o mundo se apresentam; 
d) Noção de membro: membro é o ator social que compartilha a linguagem de um grupo, mesmo que isto não signifique, necessariamente, pertencer a um determinado grupo, ou conviver no mesmo espaço geográfico. Exibir a noção de pertencimento é fundamental em etnometodologia, já que a mesma é condição prévia para se proceder às atividades de análise e descrição das ações sociais, junto a um grupo de pessoas que apresentam determinadas características que se deseja pesquisar. As implicações dessa exigência são numerosas, mas uma das mais importantes é a que faz referência à linguagem natural do grupo pesquisado. Recomenda-se que o pesquisador domine a linguagem natural do grupo, a qual possui uma série de termos indiciais e também aprenda a relatabilidade (accountability) do grupo. A pesquisa com os leitores entende como membro do grupo pesquisado o leitor de histórias em quadrinhos de super-heróis, que seja capaz de reconhecer elementos presentes deste gênero, como seus personagens - heróis, vilões, anti-heróis, coadjuvantes - suas posturas, interações e motivações, dentre outros traços. Considera-se pertinente também os momentos em que, segundo falas dos próprios leitores, pode-se constatar a introjeção do conhecimento adquirido via leitura, como, por exemplo, a incorporação de falas ou das atitudes de um ou mais personagens dos quadrinhos frente a uma situação vivida pelo leitor no seu dia a dia. Na visão da pesquisa, inclusive, tal constatação compartilhada pelo leitor é o que o torna membro da comunidade de leitores de quadrinhos de super-heróis;

e) Relatabilidade (accountability): capacidade de compreender como os atores pesquisados descrevem suas atividades práticas, expressando e compartilhando referências de sentido e de significado que possuem. Para que os atores possam descrever, interpretar, explicar ou falar sobre o mundo social em que se inserem, é necessário que este esteja disponível a eles, sendo portanto inteligível e passivo de descrições, análises e observações. É preciso frisar que a relatabilidade não é algo simplesmente fornecido pelo grupo que se pesquisa. Para Garfinkel (1963), ela é uma realização prática dos atores sociais em interação, ou seja, ocorre quando existe o compartilhamento de ações mútuas, evidenciando a lógica do senso comum que esses atores empregam para se fazer compreender. Dessa forma, a relatabilidade não é uma instância dada, mas sim produzida e construída, quando se é capaz de contemplar o mundo social como produto das atividades práticas dos atores (p. 47). 
Uma aproximação inicial junto à relatabilidade se processa na representação do mundo que um indivíduo exibe em sua mente, a qual lhe fornece base para a tomada de decisões junto a situações que acontecem no cotidiano. Focando nas histórias em quadrinhos de super-heróis, procurou-se dar ênfase às entrevistas que evidenciassem as experiências dos leitores junto à leitura, em especial aquelas que denotassem realidades específicas, quando os leitores estabelecessem paralelos entre o conteúdo lido nos quadrinhos e realidades ou momentos específicos de suas vidas. Graças a essa constatação, é possível afirmar que a visão fornecida pela relatabilidade é a representação de um universo onde se percebe a apropriação de informação e a introjeição do conhecimento por parte do leitor, como resultado da leitura desses quadrinhos e o reconhecimento de ações fundamentadas no mundo real pelos leitores, com embasamento parcial ou integral via conhecimento adquirido na leitura.

\section{Pesquisa de campo junto aos leitores de histórias em quadrinhos de super-heróis da Marvel e da DC Comics}

Ao definir histórias em quadrinhos, Eisner (1999) cunhou o termo arte sequencial, ressaltando à capacidade de narrar fatos e acontecimentos através da combinação de palavras e imagens, retratadas de forma justaposta e em sequência deliberada. McCloud (2005) expande tal noção a uma definição mais característica, quando afirma que as figuras em sequência são hoje reconhecidas como ferramenta de comunicação ${ }^{2}$. Revelando a extensão de seu pensamento, McCloud (2005, p. 20) cunhou a definição de histórias em quadrinhos como sendo "[...] imagens pictóricas e outras, justapostas em sequência deliberada, destinadas a transmitir informações e/ou produzir uma resposta no espectador".

A definição de McCloud considera os quadrinhos como um instrumento na produção e transmissão do conhecimento, capaz de fornecer a seus usuários a atribuição de sentidos e a formação de caráter. A narrativa combinada de imagens e textos dos quadrinhos apresenta formas de alcançar um significado através de sua própria subjetividade. A presença do leitor no decorrer da leitura, contribui para a sua correlação e identificação com as situações retratadas nos quadrinhos, que o remete, muitas vezes, aos acontecimentos de sua vida cotidiana.

Ainda no estudo das histórias em quadrinhos, Vergueiro (2016) explica que várias parcelas da sociedade aparentam uma rejeição quanto ao quadrinhos, talvez pela incapacidade de seus representantes de constatar sua importância na veiculação de informações, bem como na ${ }^{2}$ Como em um avião, por exemplo, onde várias das instruções são disponibilizadas em um panfleto ilustrado
com desenhos em sequência, demonstrando o que o passageiro deve fazer em caso de uma emergência. 
interpretação e introjeção do conhecimento por parte dos leitores. O autor esclarece que, no seu entender e em contraponto, uma das vantagens desse formato de leitura tem relação com o reconhecimento de que as histórias em quadrinhos cresceram exponencialmente, indo ao encontro de necessidades do ser humano, como a de habilitar a transmissão e veiculação de informações ao seu leitor.

O estímulo e aviabilidade para pesquisar a figura do leitor se deu por meio da combinação de duas ferramentas metodológicas. A primeira foi a observação participante, empregada para acessar e contemplar as atividades, os locais, os interesses e os diálogos demonstrados pelos leitores, quando eles se encontravam entre si ou mesmo diante dos quadrinhos. A segunda foram as entrevistas, encaradas como mecanismo capaz de fornecer dados importantes para se compreender de forma pormenorizada o conjunto de crenças, valores, atitudes e também motivações dos leitores, em seus contextos e histórias de vida. Essa ferramenta teve por base o conceito de história de vida tópica, que possui o foco no retrato de uma determinada experiência vivida, no caso voltada para a leitura das histórias em quadrinhos de super-heróis e as relações estabelecidas pelos leitores entre o conteúdo lido e aplicações do mesmo em suas vidas.

O acesso e a obtenção dos dados junto aos leitores de histórias em quadrinhos de super-heróis da Marvel e da DC Comics ocorreu em três diferentes localidades. Nos EUA, os leitores foram abordados no ano de 2015 nas cidades de Urbana e de Champain - Illinois. No Brasil, a mesma abordagem ocorreu ao longo do primeiro semestre de 2016, na cidade de Belo Horizonte - MG, e no segundo semestre do mesmo ano na cidade de Goiânia (GO). Ao todo foram entrevistados 44 leitores, de ambos os sexos, com idades alternando entre os 19 e os 57 anos. O número de participantes variou de acordo com o critério de saturação, o qual, segundo Morse et al. (2002), contempla o acúmulo de experiências como fonte capaz de estimar o ponto em que as informações obtidas pouco ou nada mais são capazes de acrescentar em termos de relevância ao tema ou aos objetivos de pesquisa.

Para comprovar as possíveis formas como a leitura dos quadrinhos é utilizada, após o relato da sua história de vida das leituras, foi solicitou aos entrevistados que descrevessem uma ou mais situações que eles se lembravam de ter lido em um ou mais quadrinhos. Após isso, era solicitada a ligação entre o ocorrido e a revocação dessa leitura, em determinadas experiências, percepções ou atitudes praticadas no seu dia a dia.

Os termos-chave etnometodológicos foram associados às respostas fornecidas pelos leitores, o que acaba por não somente exemplificar seu uso, mas também apresentar o maior embasamento e repercussão dos fundamentos da etnometodologia. Tal estratégia funcionou como um meio de acesso para comprovar as formas empregadas pelos leitores, para interpretar o que fora lido no quadrinho e retratar a maneira como suas percepções e interpretações, tanto dos acontecimentos narrados quanto do seu próprio mundo, estão conectadas. 
Na pesquisa de campo, foram escolhidos 44 depoimentos de leitores dentre os entrevistados, porém e a título de ilustração, foram escolhidos quatro trechos dentre todas as entrevistas, um leitor de cada uma das cidades onde se desenvolveu a pesquisa, apresentados a seguir. Dessa forma, contempla-se de forma igualitária cada uma das localidades onde a pesquisa ocorreu, respeitando assim a representatividade de cada uma delas. São também apresentados elementos chave da etnometodologia identificados nos relatos dos leitores, tendo como base de referência para a divagação do leitor a sua escolha de personagens e a inferência, lembrança deste, em fatos do seu cotidiano.

\section{Relato 1:}

Leitora: mulher norte-americana.

Local da entrevista: Urbana - Illinois.

Idade: 24 anos.

Personagem relatado: Batmoça / Oráculo.

"[...] quando eu lia a Batmoça, era divertido me imaginar como ela [...] quando eu estava na Escola de Biblioteconomia, e durante uma questão de referência em que particularmente obtive sucesso, é sempre divertido imaginar a si mesma como a Oráculo, meio que hackeando e encontrando informações".

Termos-chave da etnometodologia presentes no depoimento:

Ação prática / realização: a leitora compartilha de uma prática recorrente no contexto da Biblioteconomia, que é a de lidar com questões relativas a referências, inclusive ter que localizá-las para obter sucesso. Ao se realizar que na prática que a Batmoça / Oráculo atua de forma semelhante, buscando por informações, a leitora indicou a sua própria experiência bem sucedida na Escola de Biblioteconomia como parte de seu cotidiano, compreendendo a similaridade entre a sua atuação na busca por informação ou referência e a que a Batmoça / Oráculo também realiza.

Indexalidade: a busca por informação é uma ação ampla, que pode carregar múltiplas conotações e ser aplicada em diversas circunstâncias. Na Biblioteconomia, essa ação possui alguns significados em particular, dadas as devidas circunstâncias. Assim, sua compreensão pode ocorrer tanto como ela mesmo o fez, respondendo a uma questão de referência na Biblioteconomia, quanto do modo como Oráculo procede, que é o de "hackear". Os termos "hackear" e referência tratam-se de figuras de linguagem empregadas no intuito de descrever mais pormenorizadamente o processo de busca por informação.

Reflexividade: a ação desempenhada pela leitora - proceder a resolução de uma questão de referência na Escola de Biblioteconomia, provocou uma reação de sua parte junto à Batmoça / Oráculo. Quando a personagem procede a busca por informações e as encontra, trata-se de uma prática comum a este grupo de profissionais, e portanto capaz de 
produzir reações positivas junto à leitora, como o divertimento apontado por ela ao se imaginar como Batmoça / Oráculo.

Noção de membro: A leito aponta a facilidade e o prazer de um exercício de imaginação pessoal, ao se comparar a Batmoça / Oráculo. Isso se dá de uma maneira mais peculiar pelo fato de ambas, leitora e personagem, compartilharem de uma mesma formação acadêmica, como bibliotecárias. Assim sendo, ambas compartilham da linguagem e procedimentos pertinentes ao grupo profissional em que se inserem, 0 que reflete, no depoimento acima, na comparação de um procedimento comum à Biblioteconomia, buscar informações ou referências e obter sucesso na busca.

Relatabilidade: ambas, leitora e personagem, compartilham de uma atividade prática pertinente ao grupo profissional a que pertencem, como bibliotecárias, que é a de buscar por informações. Assim, é pertinente para essa leitora descrever essa prática a partir de dois termos - referência e "hackear" - compartilhando-os como ações imbuídas de sentido e significado mútuos, as quais carregam a evidência do senso comum que a leitora se vale para ser compreendida na comparação entre si mesma e a personagem.

\section{Relato 2:}

Leitor: homem norte-americano.

Local da entrevista: Champaign - Illinois.

Idade: 38 anos.

Personagem relatado: Homem-Aranha.

"[...] o mantra 'com grandes poderes, vêm grandes responsabilidades'. [...] como um professor [...] eu tenho o poder de cancelar a aula. Mas eu não tenho a responsabilidade de tentar e ajudar as pessoas que vêm a aula? [...] Penso no Homem-Aranha algumas vezes assim, onde eu me coloco: 'eu não preciso escolher a mim mesmo ao invés de outro alguém'.

Termos-chave da etnometodologia presentes no depoimento:

Ação prática / realização: o leitor se aproveita do lema que guia as ações do Homem-Aranha - 'com grandes poderes, vêm grandes responsabilidades' - e acaba por incorporá-lo à sua rotina e vida, dando um exemplo prático de experiência em sua carreira como professor, onde esse lema o inspira a se manter naquele que acredita ser o caminho correto.

Indexalidade: embora podendo ser aplicado em uma grande variedade de situações e contextos, o lema do Homem-Aranha apresenta significado particular para o leitor, que aponta se valer do mesmo desde idade jovem, trazendo da leitura das aventuras desse personagem a interpretação e o significado da frase para aplicações práticas em sua própria vida, como a que descreve de exemplo.

Reflexividade: a percepção do leitor sobre a importância e a aplicabilidade do lema do Homem-Aranha acabou por Ihe influenciar em 
momentos e escolhas de sua própria vida, como na passagem profissional em que ele mesmo afirma ter se valido desse lema como fonte de inspiração para tomar aquela que acreditava ser a decisão correta.

Noção de membro: o leitor reconhece o personagem HomemAranha e aquela que talvez seja a sua frase mais emblemática, incorporando-a em sua própria vida.

Relatabilidade: o leitor aponta o lema do Homem-Aranha, usado em várias aventuras lidas do personagem, como algo que se faz presente em sua vida. mesmo tendo tomado conhecimento desse lema em jovem idade, o leitor o trás consigo em sua vida adulta, não apenas exemplificando uma ação prática que escolheu realizar em virtude desse lema, como também a reflexão que exerceu a esse respeito, e o altruísmo que demonstra, ao final de sua fala, como uma consequência da adoção e da interpretação desse lema, advindo por meio da postura e aplicação pelo Homem-Aranha - que é invocado por ele em pensamento.

\section{Relato 3:}

Leitor: homem brasileiro.

Local da entrevista: Belo Horizonte - MG.

Idade: 21 anos.

Personagem relatado: Homem-Aranha (Miles Morales).

"Homem-Aranha Miles Morales [...] eu gostei demais. [...] ter um personagem negro, assim como principal". [...] [Entrevistador: O Miles é o seu Homem-Aranha favorito [...] por também ser um negro, ou algo mais?): "[...] o Miles, ele ter que se prová pra todo mundo, tanto pros personagens quanto pros fãs. Eu meio que me identifico com ele, como sendo eu, por exemplo, na faculdade, né? Eu estudo na [...] faculdade de Direito. [...] tem poucos alunos negros lá. E é o tempo todo isso, você tem que se prová". [...] Tem uma grande pressão. Você não pode errar, sabe? Eu sinto isso, e eu vi isso no personagem do Miles".

Termos-chave da etnometodologia presentes no depoimento:

Ação prática / realização: o leitor vê junto ao personagem Miles Morales uma reconstrução da sua própria condição, quando realiza que, tal qual o personagem dos quadrinhos, ele também é alvo de excesso de cobranças por parte de uma comunidade em geral. Dadas essas cobranças, tanto Miles Morales quanto ele próprio se sentem coagidos a ter que se provar dignos de estarem aonde estão, de forma recorrente.

Indexalidade: o preconceito e a cobrança ainda são fatos recorrentes na sociedade humana. E, no caso específico, ambos os termos são atribuídos a membros de uma raça que alcançam grandes méritos ao longo de suas vidas. Mas que, por serem ou exibirem traços tidos como fora de um determinado padrão, são pré-julgados por outros membros da comunidade, do modo que Miles Morales o é e que o leitor, diante da leitura de suas histórias, se vê retratado como alvo de preconceito similar. 
Reflexividade: o leitor, ao ler as histórias onde o protagonista é um super-herói negro, que enfrenta questões de preconceito e cobranças, se vê representado pelo personagem, já que em sua vida e cotidianos, ele também é um negro que lida com as mesmas questões. O senso comum se estabelece na visão do leitor, quando ele e Miles Morales são submetidos a questionamentos e cobranças por membros da comunidade em que vivem e atuam e quanto ao fato de naquele local exercerem funções que provavelmente deveriam estar ocupadas por outros membros da comunidade.

Noção de membro: o leitor, tendo lido diversas histórias e aventuras com a participação de Miles Morales como o Homem-Aranha, reconhece que pelo fato de este herói ser um personagem jovem e negro, acaba por ser alvo de preconceitos e de cobranças exageradas, dada a posição que alcançou. O leitor se vê representado dessa forma, incorporando a identificação um apreço pessoal por Miles Morales e pelo fato de ele permanecer como protagonista de uma história, em um dos papéis mais reconhecidos dos quadrinhos e o estar exercendo da mesma forma que Peter Parker.

Relatabilidade: tal qual Miles Morales, jovem homem negro, que teve de atuar e se provar digno do uniforme, dos poderes e do legado de Peter Parker como o Homem-Aranha, o leitor - também um jovem homem negro - se sente frequentemente cobrado por pessoas de seu meio acadêmico, por estar estudando via sistema de cotas em um curso e universidade que talvez não pudesse estar de outra forma. Mas, assim como Miles Morales, que é cobrado constantemente e não pode demonstrar erros no papel de homem-Aranha, o leitor investe na mesma atitude, já que, para ele, também não são permitidos erros de nenhuma espécie. O senso comum se dá justamente no reconhecimento dos sujeitos, da existência de pessoas no círculo social que impõem esta necessidade constante, no caso relatado pelo entrevistado, de ter que se provar digno por estar onde está e poder exercer suas funções.

\section{Relato 4:}

Leitor: homem brasileiro.

Local da entrevista: Goiânia - GO.

Idade: 20 anos.

Personagem relatado: Jubileu (X-Men).

"[...] a Jubileu $[\ldots]$ ela tava $[\ldots]$ no ônibus $[\ldots]$ o pessoal $[\ldots]$ não sabiam que ela era mutante. Falaram [...] 'Aí, esses mutantes é isso, esses mutantes é sangue', essas coisas. E ela, [...] não podia $[\ldots]$ atacar eles [...] o jeito dela não é destratar [...] como os humanos destratam ela. [...] isso aconteceu uma vez comigo [...] no ônibus. [...] as pessoas falavam dos homossexuais, que eles são sangue sujos, que não pode doar sangue. [...] Eu não vou tratar a pessoa com essa forma bruta. [...] Então, eu consenti, fiz a mesma tática da Jubileu. Consenti e fiquei na minha". 
Termos-chave da etnometodologia presentes no depoimento:

Ação prática / realização: ao se encontrar em um meio de transporte coletivo, ouvindo comentários preconceituosos quanto a sua orientação sexual, o leitor se lembrou e associou a mesma experiência que estava enfrentando aàda personagem Jubileu, reconstruindo em sua mente a narrativa de forma idêntica, pois Jubileu sofrera um preconceito tão explícito quanto ele, em mesma situação - ouvindo pessoas tecerem opiniões maliciosas em um ônibus.

Indexalidade: 0 preconceito pode se manifestar de inúmeras formas - credo, raça, cor, nível intelectual, dentre outras. Para Jubileu, se manifestou em ambiente público, ao ouvir teor de conversa explicitamente preconceituosa contra seres mutantes, cuja raça ela pertence. Para o leitor, o preconceito se manifestou de forma similar ao de Jubileu, em conversa de terceiros em transporte coletivo. Mas com a diferença que, expecíficamente no episódio narrado, o preconceito se manifestou contra sua opção sexual.

Reflexividade: saber que existe preconceito mesmo no mundo de hoje é fato publicamente conhecido. Porém, algo que assume um caráter mais pessoal é ser alvo de preconceito. Através da leitura dos X-Men, 0 leitor teve acesso ao episódio ocorrido com Jubileu, que se sentiu agredido pelas palavras de algumas pessoas em um diálogo claramente contra a raça mutante. Mas que optou por agir, segundo o entrevistado, com grandeza e não se render à raiva ou à dor que sentia, tomando satisfações de quem proferia tais palavras. A reação do leitor se deu de modo idêntico ao de Jubileu no mesmo cenário e contexto, graças, à sua percepção, de que o modo de agir da personagem dos quadrinhos era o correto.

Noção de membro: o preconceito é tema recorrente nas histórias dos X-Men, sendo bastante abordado em várias tramas e por diversos dos integrantes do grupo tendo sido alvos direta ou indiretamente de seus efeitos, pelo fato de serem membros da raça mutante. O preconceito retratado nas aventuras dos X-Men é passível de ser reconhecido pelos leitores, e no caso do leitor que concedeu o depoimento, além de reconhecer, foi sentido em situação e contexto de muita semelhança ao que a personagem Jubileu sofreu, tendo o leitor, inclusive, incorporado a própria atitude demonstrada por Jubileu diante do episódio em sua vida.

Relatabilidade: como resultado da leitura da história em que Jubileu sofre indiretamente preconceito, em local e meio de transporte públicos, pelo fato de ter nascido mutante e ser alvo de críticas maliciosas a esse respeito, o leitor, tendo ele mesmo sido alvo de preconceito, embora por situação diferente da personagem Jubileu, por ser uma mutante e ele por ser um homossexual, foi capaz de processar aquela situação e mais especificamente demonstrar a mesma reação e postura de Jubileu. Houve o estabelecimento do senso comum entre si mesmo e a personagem, pelo preconceito sofrido por ambos, e por considerar que a personagem agiu da maneira mais correta possível naquela situação. 


\section{Conclusão}

As entrevistas realizadas junto aos leitores de quadrinhos da Marvel e da DC Comics permitiram obter o necessário embasamento para a aplicação dos fundamentos da etnometodologia, fornecendo o meio de acesso para comprovar as formas empregadas pelos leitores e a capacidade para interpretar o que fora lido nos quadrinhos. Os leitores retrataram, até com certa facilidade, a maneira como suas percepções e interpretações, tanto dos acontecimentos narrados quanto do seu próprio mundo estão conectadas. Tal evidência fica clara ao se verificar o emprego do senso comum, fator fundamental de interpretação de relatos, conforme Garfinkel, estabelecido entre acontecimento narrado no quadrinho e situação semelhante ocorrida na vida do leitor.

Não são apenas os trajes coloridos, os poderes sobre-humanos e a luta do bem versus o mal os motivos pelos quais os leitores de quadrinhos de super-heróis fazem a opção por essa leitura. Todos esses fatores estão presentes e muito bem assimilados pelos leitores. Porém, é preciso destacar que nenhum deles surtiria tamanho efeito sobre os leitores na fase adulta de suas vidas, se não se considerar o que Iser (1999) pontua em sua teoria da recepção, sobre a necessidade ou característica notada no ser humano de "ficcionalizar sua existência" (1996, p. 65). Ele o faz, ao recorrer a leituras de teor e caráter ficcional. Mesmo assim, o leitor opta por continuar a leitura, pois ela é capaz de [...] dizer ou de revelar algo sobre si mesmo". (1996, p. 65-66)

O que o leitor de quadrinhos encontra nessa leitura, de acordo com a análise realizada e fincada em preceitos etnometodológicos, é a existência de diversas interações entre a leitura empreendida e fatos de sua própria vida. A pesquisa aponta que o leitor valoriza a sua leitura e evoca com facilidade tramas e nomes de personagens prediletos das histórias em quadrinhos. A última etapa da pesquisa, que era revocar algum conteúdo de leitura que foi por ele reinterpretado e aplicado em uma ou mais situações da sua vida, foi relembrado por muitos leitores entrevistados. Relataram que as situações de histórias lidas foram plausíveis de aplicação, pois apresentavam certo teor de verossimilhança com a sua história de vida.

Ressalta-se que o leitor de histórias em quadrinhos merece ser mais compreendido, por pesquisas que tenham como objetivo e enfoque de análise a sua opinião. As possibilidades de introjeção do conhecimento são possíveis de ser detetadas a partir da experiência de ler, dos relatos das histórias de seus personagens, dentre outros ganchos possíveis de ser resgatados pela leitura efetivada. Para tal, é necessário dar voz ao leitor, de modo a captar e revelar o que ele tem a dizer.

No que se refere aos quadrinhos, a primazia até então dos estudos tem seu foco voltado para análises do artefato cultural - a história em quadrinhos - em detrimento de seu público leitor. É possível afirmar ser do interesse da Ciência da Informação o aprofundamento de estudos e investigações junto à apropriação de informação e introjeção do conhecimento 
advindos de leitura, com especial foco e destaque direcionado à figura do leitor.

\section{Referências}

BARI, V. A. O potencial das histórias em quadrinhos na formação de leitores: busca de um contraponto entre os panoramas culturais brasileiro e europeu. 2008. 320f. Tese (Doutorado em Ciência da Informação) Escola de Comunicação e Artes, Universidade de São Paulo, São Paulo, 2008.

BOURDIEU, P. La distinction; critique social de jugement. Paris: Les Éditions de Minuit, 1979.

CHARTIER, R. Formas e sentido - cultura escrita: entre distinção e apropriação. Campinas: Mercado das Letras, 2003.

DUMONT, L. M. M. O imaginário feminino e a opção pela leitura de romances de séries. 1998. 257f. Tese (Doutorado em Comunicação e Cultura) - Escola de Comunicação, Universidade Federal do Rio de Janeiro / Instituto Brasileiro de Informação em Ciência e Tecnologia, Rio de Janeiro, 1998.

DUMONT, L. M. M.; ESPÍRITO SANTO, P. Leitura feminina: motivação, contexto e conhecimento. Ciências \& Cognição, Rio de Janeiro, v. 4, p. 2837, mar. 2007. Disponível em: <http://www.cienciasecognicao.org/revista/ index.php/cec/article/view/618>. Acesso em: 2 nov. 2012.

DUMONT, L. M. M.; PINHEIRO, E. G. Incursões teórico-metodológicas da etnometodologia na Ciência da Informação: aplicações em pesquisas sobre leitura. Informação \& Sociedade, João Pessoa, v. 25, p. 49-61, 2015.

EISNER, W. Quadrinhos e a arte sequencial. São Paulo: Martins Fontes, 1999.

GARFINKEL, H. Studies in ethnomethodology. Englewood Cliffs, New Jersey: Prentice-Hall, 1963.

HAVE, P. T. Understanding qualitative research and etnomethodology. London: Sage, 2004.

ISER, W. O ato da leitura: uma teoria do efeito estético. São Paulo: Ed. 34, 1996; 1999. 2 v.

McCLOUD, S. Desvendando os quadrinhos. São Paulo: Makron Books, 2005.

MORSE, J. et al. Verification strategies for establishing reliability and validity in qualitative research. International Journal of Qualitative Methods, Edmond, Canadá, v. 1, p. 1-18, June 2002. 
VERGUEIRO, W. de C. S. I am just a comic book reader who became curious. International Journal of Comic Art, Temple, CA, v. 18, p. 20-32, 2016. 